\title{
Folhas, talos, cascas e sementes de vegetais: composição nutricional, aproveitamento na alimentação e análise sensorial de preparações
}

\author{
Leaves, stalk, pell and seeds of vegetables: nutritional composition, utilization and sensory \\ analysis in food preparations
}

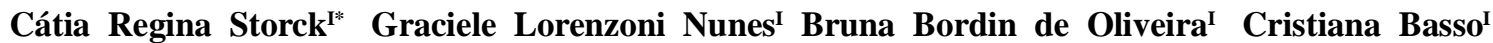

\section{RESUMO}

O objetivo deste estudo foi avaliar a composição de folhas, talos, cascas e sementes de vegetais, elaborar preparações utilizando essas partes e verificar a sua aceitabilidade. Foram selecionadas algumas frutas e hortaliças das quais foram separadas as folhas, talos, cascas e sementes. Foi analisada a composição centesimal e o teor de fenóis totais. Após, foram desenvolvidas preparações utilizando as folhas, talos, cascas e sementes, as quais foram avaliadas sensorialmente através do teste afetivo de aceitação. $O$ teor de lipídios variou de 0,03\% (talo de espinafre e talo de beterraba) a 2,27\% (semente de moranga). O teor de proteínas variou de 0,51\% (casca de banana) a 9,56\% (semente de melão). A maioria das amostras apresentou em torno de $1 \%$ de cinzas e o teor de fibras variou de $0,72 \%$ a $16,02 \%$. O teor mais elevado de polifenóis foi encontrado na casca da laranja $\left(631,25 \mathrm{mg} 100 \mathrm{~g}^{-1}\right)$. Os resultados da análise sensorial demonstraram que $77 \%$ das preparações obtiveram notas acima de 5 (gostei). Conclui-se que, através da identificação da composição nutricional das partes dos alimentos, usualmente descartadas, pode-se direcionar melhor seu uso na preparação de várias receitas.

Palavras-chave: aproveitamento integral dos alimentos, polifenóis, desperdício de alimentos, frutas, hortaliças.

\section{ABSTRACT}

The objective of this study was to evaluate the composition of leaves, stems, bark and seeds of vegetables, prepare recipes using these parts and to verify the acceptability of them. It was selected some fruits and vegetables which were separated from leaves, stems, bark and seeds. It was analyzed the nutritional composition and total phenols. After recipes were developed using the leaves, stalks, husks and seeds, which were evaluated by sensory analysis. The fat content ranged from $0.03 \%$ (stalk of spinach and beet) to $2.27 \%$ (pumpkin seed). The protein content ranged from $0.51 \%$ (banana husk) to $9.56 \%$ (melon seed).
Most samples had about $1 \%$ ash and fiber content ranged from $0.72 \%$ to $16.02 \%$. The higher content of polyphenols was found in orange husk (631.25mg) and the lowest in the papaya seed (22.53mg). It was concluded that by identifying the nutritional composition of the portions of food usually discarded the use of these parts can be better direct in preparing various recipes, which are enriched nutritionally.

Key words: whole utilization of foods, phenolic compounds, food wastefulness, fruits, plants.

\section{INTRODUÇÃO}

O desperdício de alimentos no Brasil é alto, chegando a 26 milhões de toneladas ao ano, o que poderia alimentar 35 milhões de pessoas (EMBRAPA, 2007). De cada 100 caixas de produtos agrícolas colhidos, apenas 61 chegam à mesa do consumidor (Banco de Alimentos, 2008) e 60\% do lixo urbano produzido é de origem alimentar (EMBRAPA, 2009).

As frutas que mais sofrem perdas são o abacate (31\%), abacaxi (24\%), laranja (22\%), banana (40\%), mamão (30\%), manga $(27 \%)$ e morango (39\%) (EMBRAPA, 2009). Uma maneira de evitar o desperdício seria a utilização de todas as partes dos alimentos, o que ainda é bastante discutido, já que há poucos estudos abordando o tema, principalmente em relação ao valor nutricional, preparações e receitas que utilizem folhas, talos e sementes de frutas e hortaliças. Dessa forma, as informações do valor

\footnotetext{
'Curso em Nutrição, Centro Universitário Franciscano (UNIFRA), 97010-032, Santa Maria, RS, Brasil. E-mail: catia.sm@ gmail.com.
}

*Autor para correspondência. 
nutricional dos alimentos originados da agricultura são escassas e sua utilização pequena, gerando baixo aproveitamento do alimento e desperdício de partes consumíveis (GONDIM et al., 2005).

As partes não aproveitáveis dos alimentos poderiam ser utilizadas enfatizando o enriquecimento alimentar, diminuindo o desperdício e aumentando o valor nutricional das refeições, pois talos e folhas podem ser mais nutritivos do que a parte nobre do vegetal como é o caso das folhas verdes da couve-flor que, mesmo sendo mais duras, contêm mais ferro que a couve manteiga e são mais nutritivas que a própria couve-flor (SOUZA et al., 2007). De acordo com ROCHA et al. (2008), cascas, talos e folhas são boas fontes de fibras e lipídios, tendo-se como exemplos as sementes de abóbora; talos de brócolis, de couve, de espinafre; cascas de banana, de laranja, de limão, de rabanete e folhas de brócolis.

Sendo assim, a utilização integral dos alimentos possibilita uma maneira de incrementar a culinária diária, com a criação de novas receitas como geleias, tortas, sucos, doces, além de enriquecer nutricionalmente a dieta, proporcionando mais fibras, vitaminas e sais minerais. Para a correta implantação desses alimentos no cotidiano, é preciso ter conhecimento sobre a sua composição centesimal. Portanto, o objetivo deste estudo foi avaliar a composição de folhas, talos, cascas e sementes de vegetais, elaborar preparações utilizando essas partes e verificar a sua aceitabilidade.

\section{MATERIAL E MÉTODOS}

Foram selecionados os seguintes alimentos para o estudo: moranga (Cucurbita maxima Duch) (casca e semente), batata inglesa (Solanum tuberosum ssp. Tuberosum) (casca), chuchu (Sechium edule Sw) (casca), espinafre (Brassica oleracea var. botritys) (talo), couve-flor (Brassica oleracea var. botritys) (talo e folhas), beterraba (Beta vulgaris L.) (talo e folhas), brócolis (Brassica oleracea L. var. italica Plenck) (talo e folhas), cenoura (Daucus carota L.) (talo e folhas), laranja (Citrus aurantium) (casca), banana (Musa paradisiaca) (casca), manga (Mangifera indica) (casca), melão (Cucumis melo L. var. inodorus Naud) (casca e semente), mamão papaya (Carica papaya) (casca e semente). Os vegetais utilizados na pesquisa foram obtidos em feira de produtos orgânicos no município de Santa Maria- RS. As frutas e verduras foram lavadas em água corrente, deixadas de molho em solução de água sanitária na proporção de um litro de água para uma colher de sopa de água sanitária, durante 15 minutos, e novamente lavadas em água corrente. Após, foram descascadas e as partes a serem utilizadas na pesquisa separadas. As amostras foram levadas à estufa com circulação forçada de ar a $55^{\circ} \mathrm{C}$ até a completa secagem. Foram então moídas, peneiradas e armazenadas em potes plásticos com tampa até o momento das análises. A composição centesimal foi avaliada em triplicata. As amostras para o preparo das receitas foram apenas higienizadas e sanitizadas com a solução de água sanitária na proporção de um litro de água para uma colher de sopa de água sanitária, durante 15 minutos e novamente lavadas em água corrente.

$\mathrm{O}$ conteúdo de umidade (estufa a $105^{\circ} \mathrm{C}$ por 24 horas), o teor de nitrogênio total (fator 6,25) (método no 46-13) e o teor de cinzas (método n⿳0 0801) foram determinados de acordo com a AACC (1995). O teor de lipídios foi determinado de acordo com a AOAC (1995) (éter de petróleo como solvente). A quantificação de fibra bruta foi determinada pelo método da fibra bruta (BRASIL, 1991). Os carboidratos foram calculados pela diferença dos demais componentes. Os resultados foram expressos em base úmida. $\mathrm{O}$ valor energético foi calculado utilizando-se os seguintes fatores de conversão de Atwater: carboidratos $4 \mathrm{kcal} \mathrm{g}^{-1}$, proteínas $4 \mathrm{kcal}$ $\mathrm{g}^{-1}$ e lipídios 9kcal $\mathrm{g}^{-1}$ (MENDEZ et al., 1995). A composição nutricional das partes nobres das frutas e hortaliças analisadas foram obtidas utilizando a tabela de composição de alimentos TACO (2011).

Para a análise de polifenóis, estes foram extraídos utilizando metanol $80 \%$. A concentração de polifenóis totais foi determinada pelo método colorimétrico descrito por SINGLETON \& ROSSI (1965).

Foram desenvolvidas 13 receitas utilizando as folhas, talos, cascas e sementes de frutas e hortaliças. Os ingredientes utilizados para a elaboração das receitas foram adquiridos em comércio local.

A análise sensorial foi realizada através do teste de aceitação, utilizando uma escala hedônica de sete pontos, que variou entre gostei muitíssimo e desgostei muitíssimo (DUTCOSKY, 2011). O teste foi conduzido em cabines individuais, com 40 avaliadores não treinados de ambos os sexos, que receberam as amostras não identificadas, juntamente com o termo de consentimento para a participação e a ficha de avaliação das amostras. Os avaliadores julgaram apenas a impressão geral da preparação e as amostras foram apresentadas em dias diferentes, sendo uma por dia.

Os resultados da análise sensorial foram analisados quanto à média e desvio-padrão. Foi calculado o índice de aceitabilidade das preparações 
utilizando a expressão: $\mathrm{IA}(\%)=\mathrm{Ax} 100 / \mathrm{B}$, na qual, $\mathrm{A}=$ nota média obtida para o produto e $\mathrm{B}=$ nota máxima dada ao produto (MONTEIRO, 1984).

Os resultados da composição centesimal foram analisados quanto à média das triplicatas. As informações nutricionais das preparações desenvolvidas foram calculadas utilizando os resultados obtidos para as partes estudadas e, para o restante dos ingredientes, foi utilizada a tabela de composição de alimentos da TACO (2011).

\section{RESULTADOS E DISCUSSÃO}

Os resultados da composição das partes de frutas e hortaliças encontram-se na tabela 1 . O teor de umidade variou de $56,28 \%$ (semente de melão) a $95,56 \%$ (talo de espinafre), sendo que a maioria dos vegetais apresentou umidade superior a $80 \%$. Da mesma forma, a parte nobre também apresentou valores superiores a $90 \%$ de umidade. GODIN et al. (2005) encontrou, para amostra da casca de melão,

Tabela 1 - Composição centesimal e polifenóis totais de folhas, talos, cascas e sementes de vegetais.

\begin{tabular}{|c|c|c|c|c|c|c|c|c|}
\hline & Calorias (kcal) & $\mathrm{CHO}(\mathrm{g})$ & $\mathrm{FB}(\mathrm{g})$ & $\operatorname{PTN}(g)$ & $\mathrm{LIP}(\mathrm{g})$ & $\mathrm{CZ}(\mathrm{g})$ & $\mathrm{U}(\mathrm{g})$ & PT (mg) \\
\hline \multicolumn{9}{|l|}{ Folhas } \\
\hline Couve-flor & 20,9 & 2,52 & 0,96 & 2,19 & 0,22 & 0,97 & 93,1 & 65,70 \\
\hline Beterraba & 18,3 & 2,39 & 0,72 & 1,88 & 0,13 & 1,70 & 93,2 & 28,99 \\
\hline Brócolis & 34,6 & 3,89 & 1,26 & 3,87 & 0,40 & 1,29 & 89,3 & 137,15 \\
\hline Cenoura & 40,0 & 6,91 & 1,58 & 2,82 & 0,12 & 1,71 & 86,9 & 74,79 \\
\hline \multicolumn{9}{|l|}{ Talos } \\
\hline Couve-flor & 20,8 & 3,48 & 1,29 & 1,56 & 0,07 & 0,77 & 92,8 & 66,86 \\
\hline Beterraba & 13,7 & 2,23 & 0,73 & 1,13 & 0,03 & 1,37 & 94,5 & 43,87 \\
\hline Brócolis & 18,4 & 2,99 & 1,15 & 1,48 & 0,06 & 0,93 & 93,4 & 41,40 \\
\hline Cenoura & 23,5 & 4,88 & 2,00 & 0,83 & 0,08 & 1,67 & 90,5 & - \\
\hline Espinafre & 9,3 & 1,32 & 0,89 & 0,95 & 0,03 & 1,26 & 95,6 & 25,29 \\
\hline \multicolumn{9}{|l|}{ Cascas } \\
\hline Moranga & 91,5 & 14,98 & 3,90 & 4,45 & 1,53 & 1,28 & 73,9 & 105,10 \\
\hline Batata & 52,1 & 10,45 & 0,97 & 2,40 & 0,08 & 1,05 & 85,1 & 88,44 \\
\hline Chuchu & 18,1 & 3,20 & 1,78 & 1,19 & 0,06 & 0,55 & 93,2 & - \\
\hline Laranja & 83,1 & 17,96 & 3,55 & 1,81 & 0,45 & 1,39 & 74,8 & 631,29 \\
\hline Banana & 16,9 & 2,92 & 1,00 & 0,51 & 0,35 & 1,29 & 93,9 & 38,73 \\
\hline Manga & 62,5 & 13,91 & 4,16 & 1,15 & 0,25 & 0,44 & 80,1 & 238,62 \\
\hline Melão & 18,9 & 2,13 & 4,58 & 2,03 & 0,25 & 1,19 & 89,8 & 64,85 \\
\hline Mamão p. & 26,4 & 3,35 & 2,09 & 2,76 & 0,22 & 1,67 & 89,9 & - \\
\hline \multicolumn{9}{|l|}{ Sementes } \\
\hline Moranga & 79,3 & 9,05 & 6,08 & 5,66 & 2,27 & 1,02 & 75,9 & - \\
\hline Melão & 109,0 & 15,57 & 16,02 & 9,56 & 0,94 & 1,64 & 56,3 & - \\
\hline Mamão p. & 34,5 & 0,86 & 7,33 & 4,03 & 1,66 & 1,70 & 84,4 & 22,53 \\
\hline \multicolumn{9}{|l|}{ Parte nobre } \\
\hline Couve-flor & 23 & 4,5 & 2,4 & 1,9 & 0,2 & 0,6 & 92,8 & - \\
\hline Beterraba & 49 & 11,1 & 3,4 & 1,9 & 0,1 & 0,9 & 86,0 & - \\
\hline Brócolis & 25 & 4,0 & 2,9 & 3,6 & 0,3 & 0,8 & 91,2 & - \\
\hline Cenoura & 34 & 7,7 & 3,2 & 1,3 & 0,2 & 0,9 & 90,1 & - \\
\hline Espinafre & 16 & 2,6 & 2,1 & 2,0 & 0,2 & 1,2 & 94,0 & - \\
\hline Moranga & 12 & 2,7 & 1,7 & 1,0 & 0,1 & 0,4 & 95,9 & - \\
\hline Batata & 64 & 14,7 & 1,2 & 1,8 & - & 0,6 & 82,9 & - \\
\hline Chuchu & 17 & 4,1 & 1,3 & 0,7 & 0,1 & 0,3 & 94,8 & - \\
\hline Laranja & 37 & 8,9 & 0,8 & 1,0 & 0,1 & 0,3 & 89,6 & - \\
\hline Banana & 98 & 26 & 2,0 & 1,3 & 0,1 & 0,8 & 71,9 & - \\
\hline Melão & 29 & 7,5 & 0,3 & 0,7 & - & 0,5 & 91,3 & - \\
\hline Manga & 64 & 16,7 & 1,6 & 0,4 & 0,3 & 0,4 & 82,3 & - \\
\hline Mamão & 40 & 10,4 & 1,0 & 0,5 & 0,1 & 0,4 & 88,6 & - \\
\hline
\end{tabular}

$\mathrm{CHO}=$ carboidrato; $\mathrm{FB}=$ fibra bruta; $\mathrm{PTN}=$ proteína; $\mathrm{LIP}=$ lipidio; $\mathrm{CZ}=$ cinzas; $\mathrm{U}=$ umidade; $\mathrm{PT}=$ polifenóis totais.

Ciência Rural, v.43, n.3, mar, 2013. 
teor de umidade de $93,23 \%$, valor superior ao deste estudo (89,82\%), o que pode ser atribuído a diferentes graus de maturação. Os mesmos pesquisadores encontraram teor de umidade menor na banana $(89,47 \%)$ e semelhante para o mamão $(90,63 \%)$. SOUZA et al. (2007) encontraram teores de umidade inferiores para o talo de couve-flor e brócolis.

Em relação ao teor de calorias, todas as amostras apresentaram baixo valor, ressaltando que sua adição em várias preparações não refletiria em aumento importante no valor energético. $\mathrm{O}$ alimento com maior percentual de carboidratos foi a casca de laranja $(17,96 \%)$, seguida pela casca de melão $(15,57 \%)$ e pela casca de moranga $(14,98 \%)$. O teor de carboidratos foi inferior nas folhas, talos e na maioria das cascas analisadas. Já as sementes tiveram quantidades mais elevadas quando comparadas com a parte usualmente consumida. Assim, percebese que o teor de carboidratos é baixo, o que pode ser uma vantagem para dietas de redução de peso. AJILA et al. (2008) analisaram a composição da farinha da casca de manga e encontraram $80,7 \%$ de carboidratos, enquanto que, no presente estudo, a casca da manga apresentou valor de $69,9 \%$ na massa seca, demonstrando que possivelmente tenham sido de diferentes cultivares.

O teor de lipídios das amostras variou de $0,03 \%$ (talo de espinafre e talo de beterraba) a $2,27 \%$ (semente de moranga), sendo que 16 das 19 amostras apresentaram menos de $0,5 \%$. Esse resultado mostra que essas partes podem ser usadas em preparações sem elevar o teor de lipídios. GONDIM et al. (2005) e SOUZA et al. (2007) também encontraram valores inferiores a $1 \%$ de lipídios em talos e cascas de vegetais analisados. AJILA et al. (2008) encontraram 2,2\% de lipídios na farinha da casca de manga, valor inferior ao encontrado neste trabalho, em que a casca de manga apresentou $13,16 \%$ de lipídios na massa seca. Cascas, folhas, talos e sementes, quando comparados com a parte nobre do alimento, não apresentaram variações na quantidade desse nutriente, uma vez que frutas e hortaliças não são fontes de lipídios.

A proteína é um nutriente importante para o crescimento e desenvolvimento do ser humano, portanto, alimentos que contenham maiores teores desse nutriente são importantes. O teor de proteínas nas amostras variou de $0,51 \%$ (casca de banana) a 9,56\% (semente de melão). Sendo assim, essas partes de vegetais que são geralmente desprezadas poderiam ser usadas para aumentar os teores de proteína de algumas preparações. GONDIN et al. (2005) encontraram $1,69 \%$ de proteínas na banana, valor superior ao deste estudo, enquanto que MAURO et al. (2010) analisaram a farinha de talo de couve e espinafre e encontraram valores inferiores de proteínas. Ao compararmos a quantidade de proteína encontrada nas partes descartadas em relação à parte nobre do alimento, podese observar que, para todos os alimentos analisados, o valor foi semelhante ou maior que o encontrado nas partes habitualmente consumidas.

$\mathrm{O}$ teor de cinzas reflete a quantidade de minerais presentes em um alimento. Como se pode observar na tabela 1 , a maioria das amostras apresentou em torno de $1 \%$, sendo que a semente de melão apresentou 1,71\%. GONDIN et al. (2005) e SOUZA et al. (2007) também encontraram valores próximos a 1\%, enquanto MAURO et al. (2010) encontraram valores inferiores. $O$ teor de cinzas na parte nobre do alimento foi inferior ao das suas cascas, folhas, talos e sementes, sugerindo uma quantidade de minerais relevante nessas partes.

A fibra é um nutriente que exerce várias funções benéficas ao organismo humano e os vegetais são ótimas fontes desse nutriente. Neste estudo, o teor de fibra das amostras analisadas variou de $0,72 \%$ a $16,02 \%$, sendo que a semente de melão foi a que apresentou a maior quantidade de fibra, resultado que vai ao encontro do encontrado por MELO et al. (2000), que encontraram $19 \%$ de fibra. A parte nobre dos alimentos analisados apresentou quantidades mais elevadas de fibra em relação às folhas, talos e cascas de batata e banana. As demais cascas e todas as sementes analisadas obtiveram valores superiores para esse nutriente. GONDIM et al. (2005) consideraram em sua pesquisa que as cascas de tangerina, abacate, maracujá e abacaxi são boas fontes de fibras.

Os polifenóis são substâncias reconhecidas cientificamente pelo seu potencial antioxidante, sendo encontrados principalmente em hortaliças e frutas. Neste estudo, o maior teor de polifenóis foi encontrado na casca da laranja $\left(631,25 \mathrm{mg} 100 \mathrm{~g}^{-1}\right)$ e o menor na semente de mamão papaia $(22,53 \mathrm{mg}$ $100 \mathrm{~g}^{-1}$ ) (Tabela 1). A folha de brócolis apresentou teor de polifenóis totais superior ao de seu talo, ao contrário da beterraba, que apresentou teor mais elevado no talo do que na folha. FALLER \& FIALHO (2009), ao analisarem a quantidade de polifenóis em frutas e hortaliças consumidas no Brasil, entre elas, banana, laranja, mamão, manga, brócolis e cenoura,

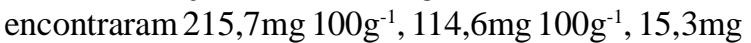
$100 \mathrm{~g}^{-1}, 110,0 \mathrm{mg} 100 \mathrm{~g}^{-1}, 68,0 \mathrm{mg} 100 \mathrm{~g}^{-1}$ e $45,1 \mathrm{mg}$ de polifenóis, respectivamente. AL-WESHAHY \& VENKET RAO (2009) analisaram a casca de seis diferentes cultivares de batata e encontraram variação na quantidade de polifenóis totais. Ao se observar os resultados do presente estudo, verifica-se que as 
partes usualmente descartadas dos vegetais contêm, de forma geral, teores de polifenóis mais altos que a parte habitualmente consumida.

Outro estudo realizado por $\mathrm{ABE}$ et al. (2007) determinou o teor de polifenóis em uvas Vitis vinifera L. e Vitis labrusca L. e encontrou quantidades de polifenóis variando de $65 \mathrm{mg}$ a $391 \mathrm{mg}$ de polifenóis/100g. Os pesquisadores SOARES et al. (2008), ao analisarem a quantidade de polifenóis extraídos com acetona $75 \%$, em cascas da uva Niágara e Isabel, encontraram $183 \mathrm{mg}$ e $197 \mathrm{mg}$ respectivamente. Portanto, quando se comparam os resultados encontrados em uvas, que são consideradas boas fontes de polifenóis, pode-se recomendar o consumo de folhas, talos, cascas e sementes de vegetais como fontes desse composto bioativo.

A tabela 2 exibe os resultados da composição centesimal das preparações elaboradas. De forma geral, a adição das partes usualmente descartadas acrescenta diversos nutrientes às preparações. O bolo de moranga com casca e o bolo de semente de mamão e de melão foram as preparações que apresentaram maiores teores de fibra bruta $(2,7 \mathrm{~g})$, uma vez que a casca de moranga e as sementes de melão e mamão apresentaram maiores valores desse nutriente. O trabalho realizado por NUNES \& BOTELHO (2009) mostrou que a elaboração de bolo com casca de banana apresentou menor valor energético, teor mais baixo de proteínas, lipídios e carboidratos, e maior quantidade de fibras, quando comparado com a preparação utilizando apenas a banana. SOUZA et al. (2007) encontraram em seu estudo maior concentração de cinzas na torta feita com $50 \%$ a mais de talos de brócolis e de couveflor e com cascas de beterraba e cenoura do que na mesma preparação sem tais ingredientes.

A tabela 3 apresenta os resultados da análise sensorial das preparações. Os resultados demonstram que $77 \%$ das preparações obtiveram notas acima de 5 (gostei). A preparação mais apreciada foi o bolo de moranga com casca e a menos aceita foi o suco de mamão com casca e limão. Esses resultados vão ao encontro de um estudo descrito por MAURO et al. (2010), que realizaram análise sensorial de cookies elaborados com farinha de talo de espinafre e talo de couve flor, em que encontraram notas acima de cinco para os dois tipos de cookies preparados. Esses resultados indicam, de um modo geral, boa aceitação das características globais das preparações desenvolvidas. Em relação ao índice de aceitabilidade, segundo MONTEIRO (1984), para que um produto possa ser considerado aceitável, é necessário que se obtenha índice de aceitabilidade de no mínimo $70 \%$. Sendo assim, apenas três preparações não obtiveram índice maior que o estabelecido como parâmetro, mostrando que a elaboração de produtos que utilizem cascas, folhas, talos e sementes foram bem aceitas.

$$
\text { NUNES \& BOTELHO (2009) }
$$

desenvolveram quatro receitas: bolo de banana; bolo de casca de banana; suco de acerola; suco de acerola, cenoura e couve, para ser avaliada a aceitabilidade por alunos de um pré-vestibular de Vitória - Espírito Santo. O grau de aceitabilidade do bolo de banana foi de $94 \%$ e do bolo de casca de banana foi de $98,8 \%$. Em relação aos sucos, a aceitabilidade do suco de acerola foi de $91,6 \%$ e do suco de acerola, cenoura e couve foi de $65,5 \%$.

Tabela 2 - Composição centesimal de preparações utilizando folhas, talos, cascas e sementes de vegetais.

\begin{tabular}{|c|c|c|c|c|c|c|}
\hline Preparações & $\begin{array}{l}\text { Calorias } \\
\text { (kcal) }\end{array}$ & $\begin{array}{c}\text { Carboidratos } \\
\text { (g) }\end{array}$ & $\begin{array}{l}\text { Fibra bruta } \\
\text { (g) }\end{array}$ & $\begin{array}{l}\text { Proteínas } \\
(\mathrm{g})\end{array}$ & $\begin{array}{l}\text { Lipidios } \\
\text { (g) }\end{array}$ & $\begin{array}{c}\text { Cinzas } \\
(\mathrm{g})\end{array}$ \\
\hline Assado de casca de chuchu com atum & 140,2 & 8,9 & 1,3 & 12,7 & 6,0 & 2,6 \\
\hline Panqueca colorida com folha e talo de beterraba & 138,3 & 26,2 & 0,5 & 3,8 & 2,0 & 3,9 \\
\hline Suflè de talos e folhas de brócolis e couve-flor & 184,5 & 28,9 & 1,3 & 7,8 & 4,2 & 6,5 \\
\hline Torta de legumes (talos e folhas de brócolis e cenoura) & 252,6 & 16,4 & 1,0 & 7,7 & 17,4 & 3,5 \\
\hline Croquete de casca de batata & 210,5 & 35,5 & 1,4 & 7,7 & 4,2 & 1,1 \\
\hline Pastel de espinafre com talos & 170,5 & 20,0 & 1,0 & 6,4 & 7,2 & 0,8 \\
\hline Bolo de casca de banana & 226,0 & 43,1 & 0,8 & 3,9 & 4,2 & 3,2 \\
\hline Bolo de laranja com casca & 338,3 & 55,3 & 1,2 & 4,5 & 11,0 & 2,8 \\
\hline Bolo de moranga com casca & 335,9 & 60,0 & 2,7 & 3,1 & 9,3 & 3,3 \\
\hline Bolo de semente de mamão e melão & 310,0 & 57,6 & 2,7 & 9,2 & 4,8 & 3,6 \\
\hline Mousse de manga com casca & 199,9 & 30,8 & 1,1 & 5,5 & 6,1 & 0,9 \\
\hline Geleia de casca de mamão & 271,5 & 65,9 & 1,2 & 1,7 & 0,1 & 1,0 \\
\hline Suco de mamão com casca e limão & 38,1 & 9,2 & 0,3 & 0,3 & 0,04 & 0,2 \\
\hline
\end{tabular}

Ciência Rural, v.43, n.3, mar, 2013. 
Tabela 3 - Análise sensorial de preparações utilizando folhas, talos, cascas e sementes de vegetais.

\begin{tabular}{lcc}
\hline Preparações & Média & $\begin{array}{c}\text { IA } \\
(\%)\end{array}$ \\
\hline Assado de casca de chuchu com atum & $5,3 \pm 1,3$ & 76,1 \\
Panqueca colorida & $5,4+1,3$ & 76,4 \\
Suflê de talos e folhas de brócolis e couve-flor & $4,6 \pm 1,3$ & 65,7 \\
Torta de legumes & $6,2+1,2$ & 88,9 \\
Croquete de casca de batata & $4,6+1,3$ & 65,0 \\
Pastel de espinafre com talos & $6,4-0,9$ & 91,1 \\
Bolo de casca de banana & $5,6 \pm 1,1$ & 79,3 \\
Bolo de laranja com casca & $5,8+0,9$ & 82,5 \\
Bolo de moranga com casca & $6,5 \pm 0,7$ & 92,5 \\
Bolo de semente de mamão e melão & $5,2+0,9$ & 73,6 \\
Mousse de manga com casca & $5,3+1,2$ & 76,1 \\
Geleia de casca de mamão & $6,1+0,8$ & 87,1 \\
Suco de mamão com casca e limão & $4,2+1,0$ & 60,0 \\
\hline
\end{tabular}

RUVIARO et al. (2008) testaram a aceitabilidade de duas sobremesas, uma padrão e outra acrescida de $1,5 \%$ de farelo de casca e bagaço de laranja entre cinquenta provadores. Os autores perceberam que a sobremesa enriquecida com o farelo obteve índices nutricionais maiores em relação à padrão, principalmente em se tratando da fibra alimentar e também que ambas as preparações obtiveram média de aceitação acima do conceito "gostei regularmente", indicando a aceitação do novo produto.

\section{CONCLUSÃO}

Considerando a importância econômica e nutricional do aproveitamento das partes usualmente desprezadas de verduras e frutas, conclui-se que, através da identificação da composição nutricional, pode-se direcionar melhor seu uso na preparação de várias receitas, as quais se enriquecem nutricionalmente.

\section{REFERÊNCIAS}

AACC (AMERICAN ASSOCIATION OF CEREAL CHEMISTS). Approved methods of the American Association of Cereal Chemists. St. Paul, MN, 1995.

ABE, L.T. et al. Compostos fenólicos e capacidade antioxidante de cultivares de uvas Vitis vinifera L. e Vitis labrusca L. Ciência e Tecnologia de Alimentos, v.27, n.2, p.394-400, 2007. Disponivel em: 〈http://www.scielo.br/pdf/cta/v27n2/31.pdf >. Acesso em: 22 fev. 2012.

AL-WESHAHY, A.; VENKET RAO, A. Isolation and characterization of functional components from peel samples of six potatoes varieties growing in Ontario. Food Research
International, v.42, n.8, p.1062-1066, 2009. Disponível em: <http:// www.sciencedirect.com/science/article/pii/S0963996909001574>. Acesso em: 04 out. 2012

AJILA, C.M. et al. Improvement of dietary fiber content and antioxidant properties in soft dough biscuits with the incorporation of mango peel powder. Journal of Cereal Science, v.48, p.319326, 2008. Disponível em: <http://www.sciencedirect.com/science/ article/pii/S0733521007001841\#>. Acesso em: 28 set. 2012.

AOAC (ASSOCIATION OF OFFICIAL ANALYTICAL CHEMISTS). Official methods of analysis. $16 \mathrm{ed}$. Washington D.C, 1995. 2v.

BRASIL. Portaria 108 de 04 de setembro de 1991. Normas gerais de amostragem para análise de rotina. Método número 11 - Fibra Bruta. Diário Oficial [República Federal do Brasil] Brasília, p.19813, 17 set. 1991. Seção 1.

DUTCOSKY, S.D. Análise sensorial de alimentos. 3.ed. Curitiba: Champagnat, 2011. 426p.

EMBRAPA (EMPRESA BRASILEIRA DE PESUISA AGROPECUÁRIA). O papel dos bancos de alimentosna reduçãodo desperdício de alimentos. Set, 2007. Disponível em: <http://pessoal. utfpr.edu.br/marlenesoares/arquivos/BancodeAlimentosEmbrapa. pdfroberto_machado_-_19.09.pdf/view>. Acesso em: 10 fev. 2012.

FALLER, A.L.K.; FIALHO, E. Disponibilidade de polifenóis em frutas e hortaliças consumidas no Brasil. Revista de Saúde Pública, v.43, n.2, p.211-218, 2009. Disponível em: <http://www. scielo.br/pdf/rsp/v43n2/207.pdf >. Acesso em: 11 fev. 2012.

GONDIM, J.A.M. et al. Composição centesimal e de minerais em cascas de frutas. Ciência e Tecnologia de Alimentos, [online], v.25, n.4, p. 825-827, 2005. Disponível em: <http://www.scielo.br/ pdf/\%0D/cta/v25n4/27658.pdf>. Acesso em: 11 fev. 2012.

MAURO, A.K. et al. Caracterização física, química e sensorial de cookies confeccionados com farinha de talo de couve (FTC) e farinha de talo de espinafre (FTE) ricas em fibra alimentar. Ciência e Tecnologia de Alimentos, v.30, n.3, p.719-728, 2010. Disponível em: <http://www.scielo.br/pdf/cta/v30n3/v30n3a24. pdf $>$. Acesso em: 13 fev. 2012.

MELO, M.L.S. de et al. Characterisation of some nutritional constituents of melon (Cucumis melo hybrid AF-522) seeds. Food Chemistry, v.68, n.4, p.411-414, 2000. Disponível em: <http:// www.sciencedirect.com/science/article/pii/S0308814699002095>. Acesso em: 28 set. 2012.

MENDEZ, M.H. et al. Tabela de composição de alimentos. Niterói: Universidade Federal Fluminense, 1995. 41p.

MONTEIRO, C.L.B. Técnicas de avaliação sensorial. 2.ed. Curitiba: CEPPA, 1984. 101p.

NUNES, J.T.; BOTELHO, R.B.A. Aproveitamento integral dos alimentos: qualidade nutricional e aceitabilidade das preparações. 2009. 64f. Monografia (Especialização em Qualidade em Alimentos) - Curso de Pós-graduação em Turismo, Universidade de Brasília, DF.

ROCHA, S.A. et al. Fibras e lipídios em alimentos vegetais oriundos do cultivo orgânico e convencional. Revista SimbioLogias, v.1, n.2, p.1-9, 2008. Disponível em: <http://www. 
ibb.unesp.br/Home/Departamentos/Educacao/Simbio-Logias/ ARTIGO_NUTR_fibras_lipidios_alimentos_vegetais_oriundos. pdf>. Acesso em: 8 fev. 2012.

SINGLETON, V.L.; ROSSI, J.A.J. Colorimetry of total phenolics with phosphomolybdic-phosphotungstic acid reagents. American Journal of Enology and Viticulture, v.16, n. 3, p.144-158, 1965. Disponivel em: <http://garfield.library.upenn.edu/classics1985/ A1985AUG6900001.pdf>. Acesso em: 28 jan. 2012.

SOUZA, P.D.J. et al. Analise sensorial e nutricional de torta salgada elaborada através do aproveitamento alternativo de talos e cascas de hortaliças. Alimentação e Nutrição, v.18, n.1, p.5560, 2007. Disponível em: <http://serv-bib.fcfar.unesp.br/seer/
index.php/alimentos/article/viewFile/133/143>. Acesso em: 24 jan. 2012.

SOARES, M. et al. Compostos fenólicos e atividade antioxidante da casca de uvas Niágara e Isabel. Revista Brasieira de Fruticultura, v.30, n.1, p.59-64, 2008. Disponível em: <http://www.scielo.br/pdf/ rbf/v33n4/v33n4a21.pdf>. Acesso em: 19 fev. 2012.

RUVIARO, L. et al. Análise sensorial de sobremesa acrescida a farelo de casca e bagaço de laranja entre universitários de Guarapuava (PR). Salus, v.2, n.2, p.41-50, 2008. Disponível em: <http://revistas.unicentro.br/index.php/salus/article/view/880>. Acesso em: ago. 2012.

TACO. Tabela brasileira de composição de alimentos. 4.ed. Campinas: NEPA-UNICAMP, 2011. 161p.

Ciência Rural, v.43, n.3, mar, 2013. 